\title{
Os bebês e a brincadeira livre na creche: concepções e práticas - apontamento para as Políticas Públicas da Infância ${ }^{1}$
}

\author{
Maria Ephigênia de A. C. Nogueira ${ }^{2}$ \\ Andréa Costa Garcia ${ }^{3}$
}

\begin{abstract}
RESUMO
$\mathrm{O}$ artigo relata uma pesquisa de observação com bebês de 1 a 2 anos de idade e a brincadeira livre na creche. $\mathrm{O}$ trabalho de observação foi desenvolvido em um Centro de Educação Infantil da rede pública da cidade de São Paulo, de fevereiro de 2013 a dezembro de 2014. Por meio do questionamento da liderança formal da creche sobre o brincar livre, buscou-se compreender os espaços, brinquedos e materiais à disposição dos bebês, concebidos como sujeitos criativos e em interação. Com metodologia de abordagem qualitativa, envolvendo estudo de caso único e investigação-ação, as concepções dos educadores em relação ao espaço, brinquedos, brincadeiras, papel do adulto na mediação foram se transformando a partir do apoio à liderança formal da escola. A formação continuada, o desenvolvimento profissional, a cultura docente e a cultura institucional se reorganizaram a partir de concepções e práticas favoráveis à autonomia dos bebês.
\end{abstract}

Palavras-chave: bebê, espaço, brinquedo

ABSTRACT

The article reports an observation survey of babies 1-2 years old and the free play in the nursery. The observational study was conducted in a Children's Educational Center of the public network in São Paulo, from February 2013 to December 2014. Through the questioning of the formal leadership of the nursery on the free play, he attempted to understand the spaces, toys and materials available to babies, conceived as creative subjects and interaction. With qualitative approach methodology, involving single case study and action research, the views of teachers in relation to space, toys, games, adult role in mediation were turning from supporting the formal leadership of the school. The continuing education, professional development, teaching culture and institutional culture reorganized from conceptions and practices favorable to the autonomy of babies.

Keywords: child, toy, space

\footnotetext{
$1 \quad$ Este trabalho é fruto de pesquisa profissional realizada de fevereiro de 2013 a dezembro de 2014 no Contexto Integrado de Educação Infantil (Ciei) Feusp e Universidade Paulista.

2 Doutora em Educação, Pesquisadora do Contexto Integrado de Educação Infantil - (Ciei) Feusp e Docente no Ensino Superior - Universidade Paulista, Pesquisadora Grupo de Políticas Públicas, Gestão e Formação de Professores -Universidade Paulista. E-mail: meacnog@uol.com.br

3 Mestranda em Educação, Pesquisadora do Contexto Integrado de Educação Infantil - (Ciei) Feusp e Supervisor Escolar na rede municipal de São Paulo. Email: jrnand@uol.com.br
} 


\section{Introdução}

O presente artigo aborda a pesquisa sobre a qualidade do espaço do brincar, dos brinquedos e das brincadeiras para bebês de 1 a 2 anos, a partir do estudo das concepções e práticas educativas das lideranças formais da creche - diretora e coordenadora pedagógica e das professoras. A pesquisa foi desenvolvida em um Centro de Educação Infantil - CEI, da rede pública da cidade de São Paulo, de fevereiro de 2013 até dezembro de 2014. O interesse surgiu do trabalho colaborativo de duas pesquisadoras, uma atuando no ensino superior, visando a aproximações da prática educativa das instituições de atendimento à primeira infância e suas concepções; a outra na supervisão escolar da rede municipal de ensino, com o objetivo de ampliar a compreensão teórica sobre a prática educativa dos profissionais em relação ao brincar. O objetivo compartilhado consiste em articular as produções teórico-metodológicas com o cotidiano da educação infantil, as concepções e as práticas educativas dos profissionais da instituição em relação ao brincar, discutindo o ambiente da creche, o espaço e objetos para o brincar livre dos bebês de 1 a 2 anos. A metodologia de pesquisa é de abordagem qualitativa, de inspiração etnográfica, com estudo de caso único, com a participação das pesquisadoras em momentos de observação das atividades cotidianas e nos encontros formativos de professores e equipe gestora da escola, em investigação-ação. A discussão da obrigatoriedade escolar das crianças a partir dos 4 anos, da pré-escola, a partir de 2016, deixa uma grande pergunta sobre a creche e seu papel como primeira etapa da educação infantil na educação básica brasileira. Esta pesquisa pretende mostrar a importância da prática educativa escolar junto às crianças da creche, com a proposta de uma pedagogia-em -participação, considerando as crianças como agentes e construtoras de cultura infantil, criativas e expressivas. Os ambientes enriquecidos para o brincar infantil, mediante o trabalho pedagógico desenvolvido pelas professoras, propõem aprendizagens que impulsionam o desenvolvimento infantil e oferecem uma prática educativa de qualidade para a criança pequena.

\section{Justificativa}

O relato da liderança formal da escola indicava a necessidade de desenvolver um trabalho de qualidade junto às crianças atendidas, no brincar livre infantil.

Havia na cultura institucional uma ênfase no que se refere a padrões de higiene, limpeza e organização no CEI, o que de forma associada gerava uma insatisfação dos educadores em relação ao tempo institucional, considerando que ele envolvia inúmeras ações de cuidado como: alimentação, trocas, higiene, sono, organização e que isto dificultava a organização de uma rotina que valorizasse momentos específicos para o brincar livre. $\mathrm{O}$ pouco tempo restante era dedicado a atividades dirigidas de acordo com o plano de trabalho.

A maior dificuldade foi apontada pelas educadoras do berçário, as quais afirmavam ser bem difícil garantir momentos de brincadeira livre, por não terem brinquedos para todos e pelas dificuldades das crianças em dividir os brinquedos e brincarem juntas. Referiam-se às crianças como egocentradas, mimadas e muito "choronas". A fala recorrente concebia o brincar como um "peso", ainda que defendessem a importância de garantir esses momentos.

As formas de ocupação do espaço também foram apontadas pela equipe como um problema a ser enfrentado. Nas salas de atividades, os brinquedos e os objetos eram 
oferecidos pelo professor, em momentos e com formas pré-estabelecidas e não estavam acessíveis aos bebês, o que, segundo a equipe gestora, precisava ser revisto, porém reiteravam sua dificuldade em visualizar e implementar diferentes formas de organização do espaço coletivo que favorecesse o brincar e as interações.

Além da necessidade apontada pela instituição, a pesquisa justifica-se pelo pequeno número de estudos no que se refere à educação de bebês no Brasil e da concepção apresentada pelos educadores quanto às possibilidades ou não de aprendizagem dos bebês na creche. Na pesquisa concebemos os bebês como seres ativos, curiosos, criativos, capazes e competentes, com desejo de conhecer e explorar o mundo de forma singular e contextualizada. Pretende-se assim ampliar os conhecimentos a respeito da educação de bebês em espaços coletivos, destacando a escola como segunda instituição social que a criança frequenta. Considerando a criança como ser integro, os educadores passam a ocupar relevante papel de mediação, seja na montagem do espaço da brincadeira ou na permissão para o brincar, pois esse espaço, pode tornar-se, com a mediação do adultoprofessor, um ambiente para brincar, com cenários que propiciam vivências e experiências cotidianas, promovem o desenvolvimento do repertório infantil e de aspectos culturais. Nesse sentido, a escola se torna um espaço de desafios e explorações, assim como de construção de si, do outro e do mundo.

Justifica-se assim a pesquisa, pela necessidade de reconfigurar o ambiente da creche, como um espaço enriquecido em cenários, objetos, mediações e possibilidade de exploração livre como parte integrante do trabalho educativo (KISHIMOTO, 2012). Os bebês, como seres ativos, curiosos, criativos, capazes e competentes, com desejo de conhecer e explorar o mundo de maneira singular e contextualizada, e a escola, como local privilegiado de vivências, experiências e conhecimento do mundo.

Apresenta-se pela pesquisa a importância da creche como espaço educativo e primeira etapa da educação infantil e da educação básica. Reitera-se a concepção de educação básica, como a base para a construção da cidadania plena, respeitando o direito de aprender, desde a creche até o final do ensino médio.

\section{Objetivos}

A investigação está voltada ao bebê, em brincadeira livre, no espaço da creche e às concepções das professoras diante desse brincar.

O objetivo é compreender o papel da liderança formal da creche e dos professores, como parceiros e mediadores das brincadeiras infantis.

A pesquisa propõe a discussão sobre concepções teóricas sobre o brincar e a qualidade do brincar, tendo o bebê como sujeito e a infância como categoria sóciohistórica associada à análise de concepções das professoras e como essas se refletem na prática educativa.

A pesquisa volta-se ao questionamento do papel da creche enquanto escola, ao discutir a qualidade do brincar na instituição escolar. Ao promover um trabalho educativo de qualidade, aponta para respostas às políticas públicas para a pequena infância. Explicita sua importância ao oferecer um ensino de qualidade à primeira etapa da educação infantil, como nível inicial e básico de toda a escolaridade composta pela educação básica brasileira. 


\section{Referencial teórico}

Os autores que oferecem sustentação teórica ao trabalho são Kishimoto (1990, 2007); nas discussões sobre jogo, brinquedo e brincadeira, Sarmento (2008); Forneiro (1998), Qvortrup (1995), na consideração da criança como agente, com direitos e destacando-se como um deles o brincar, que ocorre em um contexto social, histórico e cultural e a infância como etapa da vida. Bandiolli e Mantovani (1988) tratam do desenvolvimento do bebê, assim como Goldschmied \& Jackson (2006); Kishimoto (2012), que exploram as atividades dos bebês nas creches, as práticas educativas mais significativas que promovem o desenvolvimento e a aprendizagem infantil. A prática educativa e o desenvolvimento profissional no sentido de uma pedagogia-em-participação Oliveira-Formosinho, Kishimoto e Pinazza (2007), nos trazem o desafio da aprendizagem em companhia, no coletivo da escola. A metodologia de pesquisa terá a fundamentação teórica nos autores Denzin e Lincoln (2006), os estudos de caso, investigação ação, com Formosinho-Oliveira, Kishimoto (2002), Yin, 2005 e Stake, 1999. Formosinho, 2009, aponta os referenciais teóricos para a discussão sobre o papel da creche e da formação continuada de professores e outros agentes educativos para o desenvolvimento profissional, a transformação da cultura docente e da cultura organizacional a favor da aprendizagem e do desenvolvimento infantil na creche, como eixos da transformação educacional voltada à democracia, cidadania e dos direitos de aprendizagem das crianças pequenas e dos profissionais da educação escolar presentes na escola.

\section{Metodologia}

O projeto foi delineado em conjunto, pelas pesquisadoras e equipe do CEI. A pesquisa foi organizada a partir de duas frentes de atuação, uma com os bebês e outra com os educadores.

Os encontros formativos tinham como objetivo problematizar a visão de criança, discutir as necessidades formativas da primeiríssima infância e o brincar livre em uma perspectiva em que o currículo foi repensado, a partir da organização dos espaços, do tempo, dos materiais e das mediações necessárias para um brincar de qualidade.

A pesquisa se caracterizou como investigação de inspiração etnográfica, a partir de uma abordagem qualitativa, tendo o estudo de caso como uma das modalidades e, enquanto lócus, um caso único no espaço de uma instituição de educação infantil CEI (centro de educação infantil), mais especificamente um agrupamento de berçário II, formado por nove bebês de 1 a 2 anos de idade, que conta com a presença de uma professora, que será acompanhada nas atividades de atividades livres, de uma a duas vezes por semana, totalizando duas horas semanais

Para Oliveira-Formosinho, ao considerar a pessoa dentro de um contexto educacional e social, e ao realizar a pesquisa, apresenta no seu modus faciende operatório, a possibilidade de desenvolver uma abordagem ecológica e sócio-construtivista. A abordagem ecológica e sócio-construtivista tem como conteúdo a ser estudado a história de formação e profissão docente, sendo os instrumentos para o estudo de caso, a coleta, análise e interpretação da informação. As técnicas utilizadas são de observação do cotidiano da creche, nas atividades das brincadeiras livres das crianças, de entrevistas semi-estruturadas, de narrativas e de histórias de vida profissional, da coordenação pedagógica e das professoras e da participação nas reuniões de formação continuada. 
A imersão do pesquisador na realidade a ser problematizada, com o intuito de conhecer, descrever e analisar as relações e experiências vividas por bebês de 1 a 2 anos de idade e seus professores, em relação à brincadeira livre, em instituições de educação coletiva, surge como elemento importante no desenvolvimento da investigação-ação.

Como recursos metodológicos foram utilizados os seguintes procedimentos para coleta dos dados: observações participantes, anotações e descrições de cenas em diário de campo e fotografias. Essas estratégias foram escolhidas por possibilitarem a compreensão das relações estabelecidas entre as concepções e as práticas desenvolvidas junto ao brincar livre na creche.

Por meio delas, destaca-se a qualidade do trabalho educativo, por meio do desenvolvimento profissional, atuando na cultura docente e tornando a escola uma organização aprendente constituindo uma cultura institucional de real transformação e mudança no sentido de garantir o direito a aprendizagem, pelos eixos do brincar e da interação.

\section{Desenvolvimento da pesquisa}

A primeira etapa consistiu em entrevistas com a equipe gestora e as educadoras do berçário, que estariam envolvidas mais diretamente na pesquisa e análise documental do Projeto Pedagógico da Unidade e Plano de Trabalho da Instituição.

O Projeto Pedagógico da Instituição refere-se às Diretrizes Curriculares Nacionais para Educação Infantil, considerando as brincadeiras e interações como eixos da prática pedagógica, com definição de momentos para brincadeiras diariamente no parque e na sala, o que, por outro lado, segundo os próprios educadores, muitas vezes não acontecia, pois passavam uma grande parte do tempo nas ações de cuidado e organização do ambiente.

Na leitura do projeto político pedagógico da creche há a referência ao brincar livre na proposta pedagógica e no horário das rotinas das turmas na escola. A queixa da coordenação pedagógica sobre o brincar livre se detinha na pergunta sobre a compreensão da concepção do brincar pelas professoras e como essa compreensão se revelava no cotidiano da creche. Para a coordenação, o que se revelava presente no cotidiano escolar era deficiente, e o discurso sobre o brincar havia se tornado um chavão, um slogan sem preocupação de reflexão a partir prática educativa.

Para daro apoio ao processo de formação continuada na creche e ao desenvolvimento profissional da coordenação pedagógica, a investigação partiu da discussão sobre o ambiente e como esse pode se tornar um espaço desafiador e significativo para os bebês. Para melhor concretizar a mediação junto à coordenação, partiu-se do diagnóstico realizado por ela sobre as dúvidas das professoras quanto ao brincar: "o brincar como algo sério ou não sério do ponto de vista da criança? O brincar era coisa de criança, mas como deveria ser organizado pela professora? O que se discutia como sendo as características do brincar livre infantil? Como se relacionam o brincar e a prática curricular? Quais eram as estratégias utilizadas no brincar livre?’. A partir daí, discutir as práticas e as concepções presentes no cotidiano da creche.

A segunda etapa foi iniciada com a presença das pesquisadoras junto ao grupo de bebês na observação dos momentos de brincar livre.

A Unidade possui três agrupamentos de berçário II, crianças de 1 a 2 anos de idade com nove crianças em cada um, que permaneciam juntas num mesmo salão como sala de 
referência, em um total de 27 crianças e suas três educadoras que se alternavam entre as atividades pedagógicas e de cuidado para todas as crianças.

As crianças eram mantidas grande parte do dia neste amplo salão vazio, em tempo de espera. Em outros momentos, o brincar aparecia como situação exploratória, no aguardo para troca e as educadoras se revezavam, enquanto duas trocavam as crianças ou organizavam a sala, a outra permanecia com as crianças que "brincavam livremente".

Corriam por todos os lados, aconteciam muitas disputas entre os bebês e nos momentos de atividades propostas pelas educadoras eram organizados em roda ou enfileirados, encostados nas paredes ou com o "bumbum" no chão, por solicitação das educadoras.

Os momentos de brincar, de modo geral, eram orientados e os brinquedos acondicionados em caixas, localizadas no alto dos armários ou estantes eram apresentados e distribuídos pelas professoras aos bebês, antes do início das brincadeiras.

Foram identificadas duas formas de lidar com o brincar das crianças. Uma, em que o papel das professoras consistia em distribuir materiais e controlar os bebês, orientando os comportamentos e por vezes interagindo para demonstrar alguma forma de lidar com o brinquedo ou dar orientações, mediante o "controle" do lúdico. Outra, em que as professoras se restringiam a "deixar brincar", a partir de uma concepção romântica, somente intervindo na solução de algum conflito para garantir a segurança das crianças.

Não havia diversidade de materiais ou planejamento prévio pelo professor na organização dos espaços para brincar.

Encontramos um brincar empobrecido, com poucos materiais à disposição, ainda que a escola dispusesse de um grande acervo de brinquedos, estes não estavam acessíveis às crianças em seus momentos de brincadeiras livres, que ocorriam em espaços restritos, ambientes pobres de recursos e sem mediação.

Havia desconhecimento dos educadores em relação aos interesses dos bebês e o brincar não era concebido pelas educadoras como algo potente.

Propusemos que cada grupo de nove bebês com seu educador utilizasse outros espaços da Unidade durante a jornada do dia, utilizando a sala de referência somente para os momentos de acolhida, sono e saída. A partir de então, um grupo de nove crianças e seu educador foram acompanhados pelas pesquisadoras até o final do processo de investigação.

Surgida a demanda da Unidade de novas formas de organização do acervo de brinquedos e do fato da unidade receber, durante o período da pesquisa, uma grande doação de brinquedos, procedemos ao levantamento de todo o acervo de brinquedos e dos espaços disponíveis para brincar por meio de fotos que, posteriormente, foram apresentadas e analisadas juntamente com a equipe. Surge a ideia conjunta da organização de espaços para brincar.

A modificação da organização do espaço começou na brinquedoteca e posteriormente passou a se espalhar por todos os espaços disponíveis para brincar.

Destas discussões surgiu a proposta de organização dos brinquedos disponíveis em cantinhos ou centros /áreas de brincar, com organização a partir do equilíbrio entre áreas ativas e calmas, quantidade de crianças por área.

As observações junto aos bebês se sucederam nessa nova forma de organização 
das áreas do brincar, sendo o grande divisor de águas na percepção da própria educadora, que se surpreende no primeiro momento, quando percebe que os bebês se mantinham imóveis aguardando a "ordem" da professora para desenvolver suas brincadeiras.

Por homologia de processos, os professores passam a tomar consciência do seu próprio fazer, observando as formas das crianças em interação diante do seu papel na mediação, e o quanto pode ser aquele que oferece oportunidades e situações, construindo pontes para a criança avançar em seu processo de aprendizagem. Da mesma maneira, se constituem os processos de continuidade e permanência dos bebês na brincadeira livre.

\section{Resultados}

Foi possível notar, decorrido o tempo da pesquisa, que os bebês passaram a ter a garantia de um brincar livre, mediado pelo adulto que respeita os seus interesses.

Passa a existir assim, desse ponto de vista, uma íntima relação entre os processos de aprendizagem docentes e os processos de aprendizagem dos bebês.

Após o desenvolvimento da pesquisa é possível constatar algumas transformações no contexto da prática educativa, a partir da mudança de concepção dos educadores em relação às necessidades formativas das crianças, proporcionando um redirecionamento das formas e ofertas de brinquedos e na reorganização dos tempos e espaços para o brincar livre na instituição, principalmente junto aos bebês no berçário.

O espaço anteriormente dedicado à sala de vídeo e brinquedoteca foi modificado, assim como a ação dos bebês na brincadeira livre, em que passaram a ter acesso aos brinquedos e brincadeiras segundo suas preferências e escolhas.

Os brinquedos que anteriormente permaneciam acondicionados em caixas, sendo oferecidos às crianças pelos adultos em momentos específicos, encontram-se agora disponibilizados em estantes abertas e na altura do acesso das crianças, não só na brinquedoteca, mas também nos diferentes espaços da escola e em diversos momentos do cotidiano.

As fantasias foram retiradas do baú e colocadas na arara, os brinquedos manufaturados foram disponibilizados, assim como materiais alternativos, como sucatas de diversos tipos.

Os bebês passaram a vivenciar oportunidades de criar e construir brinquedos, vivenciar cantos temáticos com personagens e atuar em cenários que enriquecem o repertório e vivências infantis, propiciando o lúdico em diferentes espaços e momentos da creche.

Os espaços da creche, antes vazios, sem identificação, encontram-se atualmente preenchidos por brinquedos e cenários que convidam ao brincar, como o parque com cavalinhos, gira-gira, amarelinha; o espaço da arte com os materiais de sucata, tintas, papéis para a pintura na parede, agora organizada para a expressão e exploração livre das crianças; o galpão de entrada e saída das crianças, com estantes e brinquedos que permitem às crianças ao entrar na escola e aguardar o horário da primeira refeição, explorando e construindo brinquedos em companhia de outras crianças, a sala de atividades com estantes e brinquedos ao alcance infantil, a brinquedoteca toda reorganizada e semanalmente oferecendo novos desafios e oportunidades de brincar livremente.

$\mathrm{O}$ choro foi minimizado, assim como as brigas entre os bebês. Segundo a 
equipe gestora, foram inclusive procurados pela vizinhança do CEI para saber o que estavam fazendo com as crianças que quase não choravam mais. A mesma sensação de contentamento foi relatada pelos pais e pode ser percebida pelas próprias observações das professoras e das pesquisadoras.

Atualmente os bebês têm iniciativa, é permitido a eles escolher o que querem brincar, elegem os seus pares, brincam e guardam os seus brinquedos em um ciclo com começo, meio e fim.

Neste sentido, destaca-se a importância da creche como local de aprendizagem e desenvolvimento dos bebês e da constituição do trabalho coletivo dos profissionais da educação presentes na escola. Revela que a busca pela qualidade do trabalho educativo da creche abrange os dois eixos propostos pelas diretrizes curriculares nacionais para a educação infantil de 2009, que são o brincar e as interações, estando esses presentes no cotidiano do trabalho educativo da creche. Reconhece-se que em cada etapa ou nível da educação básica há um processo educativo e um conteúdo próprio a ser explorado na constituição do cuidar e educar, assim como na creche.

O conceito de criança, invisível, mini adulto e que está por vir a ser um ser acabado, adulto, mudou para criança ativa, criativa, expressiva e que interage com os objetos, com as outras crianças, com os adultos e com as culturas. Assim como o conceito de infância, fase da vida desconhecida e sem especificidades e necessidades, torna-se um período rico de aprendizagens, de interações, de exploração, de vivências, comunicação, expressão e aprendizagens culturais, das linguagens que propiciam processos interpessoais. A compreensão é da criança completa, concreta e contextualizada. O conceito de infância como primeira etapa da vida adquire sentido em função de sua projeção no tempo: o ser humano pensado como um ser em desenvolvimento, em uma relação de continuidade entre o passado, o presente e o futuro. A intervenção educacional constrói-se em uma linha contínua, na qual as crianças são a possibilidade, a potencialidade do futuro, por meio da formação com base em princípios éticos, estéticos e políticos.

\section{Considerações finais}

As rotinas da escola foram se modificando, novas práticas incorporadas alteraram a forma de organização dos tempos e espaços e simultaneamente as ações e interações das crianças e de seus educadores foram potencializadas.

As relações criança e adulto se modificaram, as crianças escolhem o canto temático e o brinquedo, ao brincar, relatam os conteúdos da brincadeira, procuram o colega a partir do brinquedo, trocam os brinquedos, constroem seu espaço brincante. A criança passou a ser percebida como sujeito e construtora de seu conhecimento no espaço da escola.

Ainda estão presentes muitos objetos industrializados, por vezes longe de um ideal de infância, em espaços organizados pelos educadores, porém, considerando-se o percurso, o processo de mudança aconteceu e o grande diferencial a ser destacado é que o movimento da mudança veio da escola, de baixo pra cima.

O foco da pesquisa, de uma perspectiva colaborativa, foi potencializar a ação da escola e de seus atores. Atualmente, decorrido o tempo, a própria Unidade, no papel da coordenação pedagógica, tem buscado novas referências teóricas e metodológicas para orientar o seu trabalho, organizando encontros formativos com seus educadores em parceria com a Universidade, investindo na formação continuada e na busca constante de 
melhoria da qualidade de ensino.

Pudemos notar que o espaço do brincar para as crianças pequenas precisa da presença de muito repertórios, caracterizados pela presença na hora da brincadeira, de objetos que representem a vida real, por meio de temas, cenários presentes no ambiente que levem a criança a poder brincar com essas representações concretas do mundo, como famílias de animais, objetos de casa, do campo, dos animais da fazenda, dos animais domésticos, dos animais selvagens, livros de histórias, brinquedos tradicionais, objetos em forma de cubos, que permitam a construção de casas e outros objetos que as crianças vão descobrindo a medida que interagem com outras crianças, professores, na família e em lugares que frequenta.

Nos estudos realizados até a presente data, após dois anos de permanência na Unidade Educacional, verificamos que ainda há muito que caminhar no que se refere ao olhar da Unidade sobre o brincar livre das crianças, e que esse processo não se encerra com a retirada das pesquisadoras do campo. Há que se construir um sistema de autofuncionamento em que juntos, educadores e crianças vivam a brincadeira como um momento de aprendizagem, aprimoramento na construção de cenários, com mudanças permanentes.

A mediação do adulto se mostra cada vez mais necessária e, nessa mediação, cada vez mais é preciso assumir seu papel junto ao brincar livre infantil, para um brincar de qualidade. Seja o professor assumindo personagens, oferecendo oficinas para ampliar o repertório dos bebês ou observando os fazeres infantis para planejar sua ação educativa, incluindo cada vez mais as famílias na compreensão do brincar infantil.

O empoderamento da Equipe e consequentemente os avanços nas práticas implementadas junto às crianças foram os maiores ganhos da pesquisa.

Mais do que práticas, houve mudança nas concepções, em que os educadores passaram a confiar no brincar da criança, concebendo esse fazer infantil como algo relevante e importante, dotado de valor em si, aprimoraram o como fazer, por meio da organização de situações que oportunizam e facilitam o brincar dos bebês, passando a ensinar e aprender pelo brincar.

Opapeldas pesquisadoras aoinvestirna mudançadeconcepçõeseconsequentemente de práticas orientou o olhar desde o princípio. Não basta oferecer manuais, literaturas, bibliografias de forma apriorística, mas sim, no momento certo, apresentar elementos que podem atender às necessidades da Unidade.

Surgem bebês, aos poucos, como sujeito das experiências, processo articulado às descobertas realizadas por seus educadores.

Pode-se então responder ao questionamento sobre a importância da creche, enquanto espaço educativo, articulando o cuidar e o educar como faces de uma mesma proposta de trabalho que acontece na escola. Desta maneira, tanto os bebês como os profissionais da educação, tornam-se partícipes de um mesmo processo de construção de identidades e de culturas de infância e docente. Revelam-se competências, vivências e a proposta de um ensino de qualidade para os bebês e uma cultura organizacional que trata os profissionais da educação como sujeitos de uma pedagogia - em - participação, instituindo a práxis pedagógica, como a maneira de pensar e viver a creche.

\section{Referências}


BARBOSA, M. "As especificidades da ação pedagógica com os bebês". In: BRASIL. Ministério da Educação. Consulta pública sobre orientações curriculares nacionais da educação infantil. Brasília, DF: MEC/SEB/COEDI, 2010.

BARBOSA, M.; RICHTER, S. "Os bebês interrogam o currículo: as múltiplas linguagens na creche". In: Anais do $17^{\circ}$ Congresso de Leitura do Brasil. Campinas, SP: UNICAMP, 2009.

BONDIOLI, A.; MANTOVANI, S._Manual de Educação Infantil de 0 a 3 anos-uma abordagem reflexiva. Porto Alegre: Ed. Artmed, 1998.

BONDIOLI, A. O tempo no cotidiano infantil. Perspectivas de Pesquisa e Estudo de caso. São Paulo: Cortez, 2004.

BONDIOLI, A. "Os modos de educar". In: Ideias orientadoras para a creche: a qualidade negociada. BECCHI, Egle. et al. Campinas: Autores Associados, 2012, p. 36-41.

BONDIOLI, A.; SAVIO, D. (Orgs.) Participação e qualidade em educação da infância: percursos de compartilhamento reflexivo em contextos educativos. Tradução: Luiz Ernani Fritoli. Curitiba: UFPR, 2013.

BROUGÈRE, G. Brinquedo e cultura. São Paulo: Cortez, 2006.

DENZIN, N. K.; LINCOLN, Y. S. Planejamento da pesquisa qualitativa - teorias e abordagens. Porto Alegre: Artmed, 2006.

DEWEY, J. Experiência e Educação. SP: Companhia Editora Nacional, 1971.

FARIA, A. "Loris Malaguzzi e os direitos das crianças pequenas". In: OLIVEIRA-

FARIA, A; PALHARES, M. Educação Infantil pós LDB: rumos e desafios. Campinas: Autores associados, 2003.

FORMOSINHO, J. (coord.). Formação de Professores - Aprendizagem profissional e acção docente. Porto, Portugal: Ed. Porto, 2009.

FORNEIRO, L.I. “A organização dos espaços na educação infantil”. In: ZABALZA, M. A Qualidade na Educação Infantil. Porto Alegre: Artmed, 1998.

GOLDSCHMIED, Elinor \& JACKSON, Sonia. Educação de 0 a 3 anos: o atendimento em creche. Porto Alegre, Artmed, 2006. 
GUIMARÃES, D. Relações entre bebês e adultos na creche: o cuidado como ética. São Paulo: Cortez, 2011.

KISHIMOTO, T. M.(org.) Jogo, brinquedo, brincadeira e educação. São Paulo: Cortez, 2008.

KISHIMOTO, T. M. "Brinquedos e brincadeiras na creche". In: BRASIL, Ministério da Educação. Secretaria da Educação Básica. Organização do espaço físico, dos brinquedos e materiais para bebês e crianças pequenas: manual de orientação pedagógica: módulo 4/ $\mathrm{MEC} / \mathrm{SEB}, 2012$.

LARROSA, J. Pedagogia profana. Belo Horizonte: Autêntica, 2010.

LINO, D. “O projeto de Reggio Emília: uma apresentação”. In: FORMOSINHO. J. (org.) Modelos curriculares para a educação de infância. Porto: Porto Ed., 1998.

MALAGUZZI, L. "História, Ideias e Filosofia Básica". In: EDWARDS, C.; GANDINI, L.; FORMAN, G. As cem linguagens da criança: a abordagem de Reggio Emilia na Educação da Primeira Infância. Porto Alegre: ArtMed, 1999.

OLIVEIRA-FORMOSINHO, J. "O desenvolvimento profissional das educadoras da infância: um estudo de caso". Dissertação de Doutoramento. Braga: Instituto de Estudos da Criança, Universidade do Minho.

OLIVEIRA-FORMOSINHO, J. (org.) O espaço e o tempo na Pedagogia-emParticipação. Coleção Infância. Lisboa: Porto Editora, 2011.

OLIVEIRA-FORMOSINHO; KISHIMOTO; PINAZZA. Pedagogia(s) da infância: dialogando com o passado: construindo o futuro. Porto Alegre: Atmed, 2007.

PINAZZA, M. A. "Formação de profissionais de educação infantil em contextos integrados: informes de uma investigação-ação". Tese de Livre Docência: Feusp, 2014.

QVORTRUP, J. "Crescer na Europa. Horizontes actuais dos estudos sobre infância e juventude". In: CHISHOLM, L; KRUGER,P.; DU BOIS-RAYMOND, M. Infância na Europa: um novo campo de pesquisa social. Berlin/New York: De Gruyter, 1995, p. 7-19.

RAMOS, T; Rosa, E. Os saberes e as falas de bebês e suas professoras. Belo Horizonte: Autêntica, 2012.

RINALDI, C. Diálogos com Reggio Emilia - Escutar, investigar e aprender. Trad. Vania 
Cury, São Paulo: Paz e Terra, 2012.

SARMENTO, Manuel Jacinto (2008). "Sociologia da Infância: Correntes e Confluências". In: SARMENTO, M. J.; GOUVÊA, M. C, S. de (org.). Estudos da Infância: educação e práticas sociais. Petrópolis: Vozes (17-39), 2008.

STAKE, R.E. Investigación con estudio de casos. 2 ed. Madrid: Morata, 1999.

VYGOTSKI, L. El desarrollo de los processos psicológicos superiores. Barcelona: Crítica, 2000.

YIN, R. Estudo de caso: planejamento e métodos. Porto Alegre: Bookman, 2005. 